\title{
Hypertension and associated factors in older adults in South Africa
}

\author{
KARL PELTZER, NANCY PHASWANA-MAFUYA
}

\begin{abstract}
Background: Older adults are disproportionately affected by hypertension, which is an established risk factor for cardiovascular disease. Little attention has been focused on hypertension and associated factors among older adults in Africa. Therefore, this study aimed to investigate the prevalence and associated factors of hypertension in a national sample of older South Africans who participated in the Study of Global Ageing and Adults' Health (SAGE) in 2008.

Methods: In 2008 we conducted a national, population-based, cross-sectional study of a sample of 3840 subjects aged 50 years or older in South Africa. The questionnaire included socio-demographic characteristics, health variables, and anthropometric and blood pressure measurements.

Results: The prevalence of hypertension in the sample population was $77.3 \%$ (male $74.4 \%$, female $79.6 \%$ ). The rates of awareness, treatment and control among the hypertensive participants were $38.1,32.7$ and $17.1 \%$, respectively. The results of multivariate logistic regression analysis revealed that the prevalence of hypertension was associated with being in the Coloured population group, having had a stroke, being overweight or obese and having had five or more out-patients care visits in the past 12 months. Hypertension was inversely associated with current alcohol use.

Conclusion: This study revealed high rates of hypertension among older adults (50 years and more) in South Africa, which puts them at risk for cardiovascular disease. The percentages of hypertensive subjects who were aware, treated and controlled were very low. These data underscore the urgent need to strengthen the public health education and blood pressure-monitoring systems to better manage hypertension among older adults in South Africa.
\end{abstract}

Keywords: hypertension, risk factors, older adults, South Africa Submitted 7/4/12, accepted 11/1/13

Cardiovasc J Afr 2013; 24: 67-72

www.cvja.co.za

DOI: 10.5830/CVJA-2013-002

HIV/AIDS/SIT and TB (HAST), Human Sciences Research Council, Pretoria, South Africa

KARL PELTZER, PhD, KPeltzer@hsrc.ac.za

NANCY PHASWANA-MAFUYA, PhD

Department of Psychology, University of Limpopo, Turfloop, South Africa and ASEAN Institute for Health Development, Mahidol University, Salaya, Thailand

KARL PELTZER, PhD

Office of the Vice Chancellor, Nelson Mandela Metropolitan University, Port Elizabeth, South Africa

NANCY PHASWANA-MAFUYA, PhD
High blood pressure in South Africa is estimated to have caused 46888 deaths and 390860 disability-adjusted life years in $2000{ }^{1}$ Hypertension alone is the leading reason for attending primary care and is the most common diagnosis (13.1\%) in South Africa. ${ }^{2}$ In population-based surveys, high rates of hypertension were found among older adults in South Africa, 44.0-52.0\% among men and 51.6-60.4\% among women in $1998 .{ }^{3}$

In other countries, in Dakar, Senegal, $65.4 \%$ of subjects had hypertension, ${ }^{4}$ in urban Zimbabwe $72 \% .{ }^{5}$ In Malawi, Rwanda and Tanzania, hypertension was found in $41.0 \%$ of men and $36.6 \%$ of women. ${ }^{6}$ In Costa Rica, $65 \%$ were hypertensive, ${ }^{7}$ and $42.4 \%$ of women in Accra, Ghana had hypertension. ${ }^{8}$ In Brazil, self-reported hypertension was $55 \%,{ }^{9}$ in rural China it was 57-64.9\%, ${ }^{10}$ and in another study in China it was $24.2-43.8 \% .^{11}$ In Turkey $71.2-82.2 \%$ of subjects had hypertension, ${ }^{12}$ and in Taiwan $31.1-38.0 \% .^{13}$

Various factors have been found to be associated with hypertension, including socio-demographics (older age, female gender, lower education level, lower household income), ${ }^{13-16}$ geolocality (urban residence), ${ }^{17}$ other risk factors or behaviour, including stroke, ${ }^{18}$ diabetes,${ }^{19,20}$ higher body mass index (BMI), ${ }^{5,10,13,14}$ physical inactivity, ${ }^{16,22,23}$ insufficient fruit and vegetable intake, ${ }^{13,23-25}$ smoking and drinking, ${ }^{10,16,22}$ greater limitations on activities of daily living (ADLs) and instrumental activities of daily living (IADLs), ${ }^{26}$ higher frequency of doctor visits, ${ }^{4}$ and less social cohesion. ${ }^{27}$

In general, it is estimated that in South Africa only $26 \%$ of men and $51 \%$ of women are aware of their hypertension. ${ }^{1}$ Among older adults in Senegal, half of those suffering from high blood pressure were aware of their problem, and among the latter, 70\% said they were on treatment. However, of these, only $17 \%$ had controlled arterial blood pressure. ${ }^{4}$ Among rural older adults in China, the rates of awareness, treatment and control were very low (overall 35.2, 28.7 and $1.0 \%$, respectively). ${ }^{10}$

Few studies exist investigating hypertension among older adults in low- and middle-income countries. Yet, research studies 'demonstrate a clear evolution in the prevalence, awareness, treatment and control of hypertension during the ageing process'. ${ }^{4}$ Therefore, this study aimed to investigate the prevalence and associated factors of hypertension in a national sample of older South Africans who participated in the Study of Global Ageing and Adults' Health (SAGE) in 2008.

\section{Methods}

We conducted a national, population-based, cross-sectional study with a sample of 3840 subjects aged 50 years or older in South Africa in 2008. The SAGE sample design entailed a two-stage probability sample that yielded national and sub-national estimates to an acceptable precision at provincial level, by locality type (urban and rural) and population group (including black, Coloured, Indian or Asian, and white). The overall response rate among those aged 50 years or older was $60 \%$. 
The Global Study on Ageing (SAGE) survey was carried out in South Africa in partnership with the World Health Organisation (WHO), the National Department of Health, and the Human Sciences Research Council (HSRC). The study was approved by the Human Sciences Research Council Research Ethics Committee and the national Department of Health.

Blood pressure (systolic and diastolic) was measured three times on the right arm/wrist of the seated respondent using an automated recording device (OMRON R6 Wrist Blood Pressure Monitor, HEM-6000-E, Omron Healthcare Europe, BV, Hoofddorp and The Netherlands).

Out of three measurements, the average of the last two readings was used. In accordance with the Seventh Report of the Joint National Committee on Prevention, Detection, Evaluation and Treatment of High Blood Pressure, individuals with systolic blood pressure $\geq 140 \mathrm{mmHg}$ and/or diastolic blood pressure $\geq 90 \mathrm{mmHg}$ and/or who reported the current use of antihypertensive medication were considered to be suffering from high blood pressure. ${ }^{28}$

Awareness was defined as history of hypertension based on diagnosis by a healthcare provider. Treatment was defined as taking any medication or other treatment for hypertension in the last two weeks prior to the survey, and control was defined as blood pressure $<140$ and $<90 \mathrm{mmHg}$ at the time of the survey.

Lifetime tobacco users were asked 'Do you currently use (smoke, sniff or chew) any tobacco products such as cigarettes, cigars, pipes, chewing tobacco or snuff?' The response options were 'Yes, daily', 'Yes, but not daily' and 'No, not at all'. Daily tobacco use was coded $=1$, and not daily and not at all $=0 .{ }^{29}$

Lifetime alcohol users were asked about current (past month) alcohol use. Past month alcohol use was coded $=1$ and no past month alcohol use $=0$.

Height and weight were measured. Body mass index (BMI) was used as an indicator of obesity $\left(\geq 30 \mathrm{~kg} / \mathrm{m}^{2}\right)$, calculated as weight in $\mathrm{kg}$ divided by height in metres squared. Overweight and/or obesity were defined as BMI $\geq 25 \mathrm{~kg} / \mathrm{m}^{2}$ and underweight as $<18.5 \mathrm{~kg} / \mathrm{m}^{2}$.

Social cohesion was measured with nine items, starting with the introduction 'How often in the last 12 months have you... e.g. attended any group, club, society, union or organisational meeting?' All nine items were summed to get a social cohesion index. Response options ranged from never $=1$ to daily $=5$. Cronbach alpha for the social cohesion index in this sample was 0.73 .

Physical activity was measured using the General Physical Activity Questionnaire (GPAQ). The instrument gathers information on physical activity in three domains (activity at work, travel to and from places, and recreational activities), as well as time spent sitting. The questionnaire also assesses vigorous and moderate activities performed at work and for recreational activities. Information on the number of days a week spent on different activities, and time spent in a typical day for each activity was also recorded. ${ }^{30}$ Cronbach alpha for the GPAQ in this sample was 0.77 .

For physical activity, in addition to the total minutes of activity, the activity volume was also computed by weighting each type of activity by its energy requirement in metabolic equivalents (METs). One MET was defined as the energy cost of sitting quietly, and was equivalent to a caloric consumption of $1 \mathrm{kcal} / \mathrm{kg} / \mathrm{h}$. A MET-minute showed the total activity volume on a weekly basis, and was calculated by multiplying the time spent on each activity during a week by the MET-values of each level of activity. MET-values for different levels of activities were set as 4 MET for moderate intensity physical activity, 8 MET for vigorous physical activity, and 4 MET for transport-related walking or cycling.

The total physical activity for GPAQ2 was calculated as the sum of the total moderate, vigorous, and transport-related activities per week. The number of days and total physical activity MET-minutes per week were used to classify respondents into three categories of low, moderate and high level of physical activities. Less than 600 MET-minutes per week was classified as low physical activity. ${ }^{30}$

Fruit and vegetable consumption was assessed with the questions 'How many servings of fruit do you eat on a typical day?' and 'How many servings of vegetables do you eat on a typical day?' Insufficient fruit and vegetable consumption was defined as less than five servings of fruits and/or vegetables a day.

Overall self-rated health status was based on respondents' assessment of their current health status on a five-point scale in response to the question: 'In general, how would you rate your health today?' Response categories were: very good, good, moderate, bad and very bad. Very good and good were grouped together and coded $=1$, moderate $=2$ and bad and very bad were grouped together and coded $=3$.

Activity limitation (difficulty an individual may have in executing task or actions) was assessed with one item 'Overall in the last 30 days, how much difficulty did you have with work or household activities?' Response options ranged from $1=$ none to $5=$ extreme/cannot do. None were $\operatorname{coded}=1$, mild $=2$, moderate $=3$ and severe and extreme were grouped together and coded $=4$.

Finally, participants were asked about a list of chronic and other conditions they had been diagnosed with, including diabetes, hypertension, stroke, angina and arthritis. Of participants who responded to having been diagnosed with hypertension, the question was asked, 'Have you been taking any medication or other treatment for it during the last two weeks?' Other treatment might include a weight-loss programme or change in eating habits.

Attendance at out-patient care was assessed with the question, 'Over the last 12 months, did you receive ant healthcare not including an overnight stay in hospital or long-term care facility?' Of those who indicated 'yes' they had to report the number of times they had received healthcare or consultation in the last 12 months. Frequency of attendance at out-patient care was grouped into none $=0$, one to four $=2$, five or more $=3$.

To estimate economic or wealth status, a random-effects probit model was used to identify indicator-specific thresholds that represent the point on the wealth scale above which a household is more likely to own a particular asset than not. This enabled an estimation of an asset ladder. These estimates of thresholds, combined with actual assets observed to be owned for any given household, were used to produce an estimate of household-level wealth status. This was used to create wealth quintiles. ${ }^{31}$ Lowest and second-lowest wealth quintiles were grouped together as low $=1$, the middle wealth quintile was medium $=2$ and the fourth and highest wealth quintiles were grouped together as high $=3$.

\section{Statistical analysis}

The data were entered using CSPro and analysed using STATA Version 10. The data were weighted using post-stratified 
individual probability weights based on the selection probability at each stage of selection. Individual weights were post-stratified by province, gender and age groups according to the 2009 medium mid-year population estimates from Statistics South Africa, available at: http://www.statssa.gov.za/publications/ P0302/P03022009.pdf.

Computed estimates and odds ratios were reported with $95 \%$ confidence intervals and a two-tailed $p$-value of 0.05 was used as the cut-off point for statistical significance. Associations between key outcomes of hypertension, and socio-demographic and health variables were evaluated calculating odds ratios (OR).

Multivariate logistic regression was used for evaluation of the impact of explanatory variables for key outcome of hypertension (binary dependent variable). All variables statistically significant at $p<0.05$ in bivariate analyses were included in the multivariable models. In the analysis, weighted percentages were reported.

\section{Results}

The total sample included 3840 South African subjects 50 years or older, $44.1 \%$ were men and $55.9 \%$ were women. The most prevalent population group was black Africans (74\%), and almost half (49.9\%) were between 50 and 59 years old. The educational level of most participants $(71.6 \%)$ was lower than secondary school education and almost two-thirds (64.9\%) lived in an urban area.

A large group (72.4\%) of older adults were overweight or obese, $20.4 \%$ were daily tobacco users, $4.0 \%$ had had a stroke, and $9.2 \%$ had diabetes. More than half $(52.2 \%)$ engaged in low physical activity, two-thirds $(67.7 \%)$ ate insufficient fruit and vegetables, and a small proportion $(13.7 \%)$ were current alcohol users. A sizeable proportion $(17.5 \%)$ rated their health status as bad or very bad, $10.7 \%$ reported severe or extreme activity limitation and $28.1 \%$ were out-patients five times or more. The prevalence rates of hypertension were $77.3 \%$ (male $74.4 \%$, female $79.6 \%$ ) (Table 1 ).

The results of the multivariate logistic regression analysis revealed that the prevalence of hypertension was associated with being in the Coloured population group, having had a stroke, being overweight and having had five or more out-patients care visits in the past 12 months. Prevalence of hypertension was inversely associated with current alcohol use (Table 2).

Overall, $30.3 \%$ of older hypertensive people were aware of their diagnosis, $24.8 \%$ of older hypertensives were taking treatment in the past two weeks to lower their blood pressure, and $48.8 \%$ of those who were taking antihypertensive treatment had their blood pressure controlled. Women, older age and more frequent out-patient visits in the past 12 months were associated with awareness of their hypertensive status and were taking treatment to lower their blood pressure in the past two weeks. However, there were no statistical differences in gender, age and out-patient visits among those who were taking antihypertensive treatment and had their blood pressure controlled. Of the total 2 841 hypertensive participants, 1081 (38.1\%) were aware of their hypertension, 985 (32.7\%) were being treated, and $486(17.1 \%)$ had their hypertension under controll (Table 3).

\section{Discussion}

The study found significant rates of hypertension of $77.3 \%$ (male $74.4 \%$, female $79.6 \%$ ) among older adults (50 years and older) in South Africa. These rates seemed to be higher than in a previous survey in South Africa (men 44.0-52.0\% and women $51.6-60.4 \%$ ) in $1998,{ }^{3}$ and similar to other studies such as in urban Senegal (65.4\%), ${ }^{4}$ urban Zimbabwe $(72 \%),{ }^{5}$ and Turkey $(71.2-82.2 \%) .{ }^{12}$ The rates were higher than in a number of other countries including rural Malawi, Rwanda and Tanzania (36.6$41.0 \%),{ }^{6}$ Brazil $(55 \%),{ }^{9}$ China $(24.2-64.9 \%),{ }^{10,11}$ and Taiwan $(31.1-38.0 \%)$. $^{13}$

The study further found that regarding socio-demographics, with multivariate analysis, being in the Coloured population group was associated with higher rates of hypertension. This

\begin{tabular}{|c|c|c|c|c|}
\hline \multicolumn{5}{|c|}{$\begin{array}{l}\text { TABLE 1. SAMPLE CHARACTERISTICS AND PREVALENCE RATE OF } \\
\text { HYPERTENSION AMONG OLDER SOUTH AFRICANS }\end{array}$} \\
\hline & & \multicolumn{3}{|c|}{ Prevalence rate of hypertension } \\
\hline & $\begin{array}{c}\text { Total } \\
\text { sample }\end{array}$ & $\begin{array}{c}\text { Male } \\
(\mathrm{n}=1638)\end{array}$ & $\begin{array}{c}\text { Female } \\
(\mathrm{n}=2202)\end{array}$ & Total \\
\hline All & 3840 & $1159(74.4)$ & $1683(79.6)$ & $2842(77.3)$ \\
\hline \multicolumn{5}{|l|}{ Age (years) } \\
\hline $50-59$ & 1695 (49.9) & $520(71.3)$ & $682(77.9)$ & $1202(74.9)$ \\
\hline $60-69$ & $1233(30.6)$ & $391(79.4)$ & $563(81.6)$ & $954(80.6)$ \\
\hline 70 and over & $912(19.5)$ & $248(75.1)$ & $438(80.5)$ & $686(78.4)$ \\
\hline \multicolumn{5}{|l|}{ Population group } \\
\hline African black & $2053(74.0)$ & $575(73.1)$ & $975(80.0)$ & $1550(77.3)$ \\
\hline White & $269(9.3)$ & $92(75.6)$ & $101(83.0)$ & $193(79.6)$ \\
\hline Coloured & $655(12.8)$ & $195(88.1)$ & $350(83.1)$ & $545(85.0)$ \\
\hline Indian or Asian & $307(3.8)$ & $97(74.1)$ & $117(78.5)$ & $214(76.8)$ \\
\hline \multicolumn{5}{|l|}{ Marital status } \\
\hline Single & $512(14.3)$ & $97(71.5)$ & $292(83.1)$ & $389(80.1)$ \\
\hline Married & $2007(55.9)$ & $870(74.2)$ & $571(74.2)$ & $1441(74.2)$ \\
\hline Separated/divorced & $230(5.9)$ & $60(66.0)$ & $116(82.3)$ & $176(77.7)$ \\
\hline Widow & $1020(23.9)$ & $120(84.8)$ & $667(82.6)$ & $787(82.9)$ \\
\hline \multicolumn{5}{|l|}{ Educational level } \\
\hline No schooling & $854(25.2)$ & $231(78.3)$ & $422(81.2)$ & $653(80.2)$ \\
\hline Less than primary & $803(24.0)$ & $227(69.4)$ & $404(85.6)$ & $631(78.9)$ \\
\hline Primary & $779(22.4)$ & $232(79.2)$ & $364(79.3)$ & $596(79.2)$ \\
\hline Secondary & $923(28.3)$ & $261(74.9)$ & $337(76.5)$ & $598(75.8)$ \\
\hline \multicolumn{5}{|l|}{ Wealth } \\
\hline Low & $1482(40.6)$ & $429(71.1)$ & $646(78.7)$ & $1075(75.4)$ \\
\hline Medium & $731(18.2)$ & $197(74.7)$ & $377(79.9)$ & $574(78.3)$ \\
\hline High & $1608(41.2)$ & $525(77.1)$ & $651(80.2)$ & $1176(78.6)$ \\
\hline \multicolumn{5}{|l|}{ Geolocality } \\
\hline Rural & $1276(35.1)$ & $392(75.9)$ & $524(78.7)$ & $916(77.5)$ \\
\hline Urban & $2561(64.9)$ & $766(73.7)$ & $1157(80.1)$ & $1923(77.2)$ \\
\hline \multicolumn{5}{|l|}{ Other conditions } \\
\hline Stroke & $139(4.0)$ & $48(88.2)$ & $71(91.5)$ & $119(90.0)$ \\
\hline Angina & $219(5.2)$ & $62(76.2)$ & $114(76.2)$ & $176(76.2)$ \\
\hline Diabetes & $360(9.2)$ & $107(88.4)$ & $202(90.2)$ & $309(89.6)$ \\
\hline Overweight (BMI $\geq 25 \mathrm{~kg} / \mathrm{m}^{2}$ ) & $2505(72.4)$ & $745(77.3)$ & $1253(82.8)$ & $1998(80.5)$ \\
\hline Underweight $\left(\mathrm{BMI}<18.5 \mathrm{~kg} / \mathrm{m}^{2}\right)$ & $184(4.3)$ & $51(64.4)$ & $63(66.8)$ & $114(65.5)$ \\
\hline Arthritis & $851(24.7)$ & $198(81.8)$ & $472(83.0)$ & $670(82.6)$ \\
\hline Daily tobacco use & $810(20.4)$ & $295(74.6)$ & $315(76.3)$ & $610(75.4)$ \\
\hline Alcohol use (past month) & $557(13.7)$ & $248(66.6)$ & $151(77.5)$ & $399(70.3)$ \\
\hline \multicolumn{5}{|l|}{ Physical activity } \\
\hline Low & $2100(52.2)$ & $567(73.2)$ & $940(79.0)$ & $1507(76.6)$ \\
\hline Moderate & $692(16.6)$ & $233(79.6)$ & $302(76.9)$ & $535(78.1)$ \\
\hline High & $1044(31.2)$ & $357(73.4)$ & $440(82.1)$ & $797(78.1)$ \\
\hline Insufficient fruit and vegetables & $2817(67.7)$ & $834(77.3)$ & $1245(77.0)$ & $2079(77.1)$ \\
\hline \multicolumn{5}{|l|}{ Subjective health status } \\
\hline Very/good & $1469(37.9)$ & $486(71.3)$ & $565(75.4)$ & $1051(73.4)$ \\
\hline Moderate & $1681(44.9)$ & $495(78.2)$ & $834(80.9)$ & $1329(79.8)$ \\
\hline Bad/very bad & $617(17.5)$ & $177(73.9)$ & $281(84.4)$ & $458(79.9)$ \\
\hline \multicolumn{5}{|l|}{ Activity limitation } \\
\hline None & $1465(38.5)$ & 487 (73.6) & $566(74.8)$ & $1053(74.2)$ \\
\hline Mild & $625(16.7)$ & $191(71.6)$ & $297(80.5)$ & $488(76.5)$ \\
\hline Moderate & $1275(34.2)$ & $369(75.9)$ & $628(81.0)$ & $997(78.9)$ \\
\hline Severe/extreme & $370(10.7)$ & $103(78.5)$ & $178(89.6)$ & $281(85.8)$ \\
\hline $\begin{array}{l}\text { Social cohesion index (range } \\
9-72) \text {; mean (SD) }\end{array}$ & $22.1(6.5)$ & $21.9(6.2)$ & $21.4(6.1)$ & $21.6(6.1)$ \\
\hline \multicolumn{5}{|l|}{ Outpatient visits in past 12 months } \\
\hline 0 & $1176(38.2)$ & $372(72.2)$ & $464(74.5)$ & $836(73.3)$ \\
\hline $1-4$ & $908(33.7)$ & $271(76.2)$ & $414(79.2)$ & $685(77.9)$ \\
\hline 5 or more & $941(28.1)$ & $282(80.4)$ & $513(86.4)$ & $795(84.2)$ \\
\hline
\end{tabular}




\begin{tabular}{|c|c|c|}
\hline \multicolumn{3}{|c|}{$\begin{array}{l}\text { TABLE 2. MULTIPLE LOGISTIC REGRESSION OF HYPERTENSION } \\
\text { PREVALENCE IN OLDER SOUTH AFRICANS }\end{array}$} \\
\hline & UOR $(95 \%$ CI $)$ & $A O R(95 \% C I)$ \\
\hline \multicolumn{3}{|l|}{ Gender } \\
\hline Female & 1.00 & 1.00 \\
\hline Male & $0.75(0.57-0.98)^{*}$ & $0.85(0.80-1.63)$ \\
\hline \multicolumn{3}{|l|}{ Age (years) } \\
\hline $50-59$ & 1.00 & 1.00 \\
\hline $60-69$ & $1.40(1.12-1.75)^{* *}$ & $1.30(0.94-1.79)$ \\
\hline 70 and over & $1.22(0.87-1.70)$ & $1.19(0.80-1.78)$ \\
\hline \multicolumn{3}{|l|}{ Population group } \\
\hline African black & 1.00 & 1.00 \\
\hline White & $1.14(0.64-2.05)$ & $1.23(0.66-2.30)$ \\
\hline Coloured & $1.66(1.07-2.59)^{*}$ & $1.89(1.04-3.44)^{*}$ \\
\hline Indian or Asian & $0.97(0.59-1.60)$ & $0.82(0.47-1.42)$ \\
\hline \multicolumn{3}{|l|}{ Marital status } \\
\hline Single & 1.00 & \\
\hline Married & $0.71(0.43-1.18)$ & \\
\hline Separated/divorced & $0.86(0.43-1.72)$ & \\
\hline Widow & $1.20(0.66-2.19)$ & \\
\hline \multicolumn{3}{|l|}{ Educational level } \\
\hline No schooling & 1.00 & \\
\hline Less than primary & $1.15(0.74-1.81)$ & \\
\hline Primary & $1.18(0.86-1.60)$ & \\
\hline Secondary & $0.97(0.71-1.31)$ & \\
\hline \multicolumn{3}{|l|}{ Wealth } \\
\hline Low & 1.00 & \\
\hline Medium & $1.18(0.78-1.77)$ & \\
\hline High & $1.20(0.80-1.80)$ & \\
\hline \multicolumn{3}{|l|}{ Geolocality } \\
\hline Rural & 1.00 & \\
\hline Urban & $0.98(0.59-1.65)$ & \\
\hline \multicolumn{3}{|l|}{ Other conditions } \\
\hline Stroke & $2.67(1.10-6.47)^{*}$ & $4.48(1.48-13.59)^{* *}$ \\
\hline Angina & $0.92(0.56-1.51)$ & \\
\hline Diabetes & $2.65(1.86-3.78)^{* * *}$ & $1.30(0.86-1.98)$ \\
\hline Overweight(BMI $\left.\geq 25 \mathrm{~kg} / \mathrm{m}^{2}\right)$ & $1.67(1.41-1.98)^{* * * *}$ & $1.52(1.15-2.01)^{* *}$ \\
\hline Underweight $\left(\mathrm{BMI}<18.5 \mathrm{~kg} / \mathrm{m}^{2}\right)$ & $0.53(0.30-0.97)^{*}$ & $0.77(0.36-1.64)$ \\
\hline Arthritis & $1.49(1.06-2.11)^{*}$ & $1.13(0.75-1.69)$ \\
\hline Daily tobacco use & $0.85(0.56-1.30)$ & \\
\hline Alcohol use (past month) & $0.64(0.47-0.85)^{* *}$ & $0.64(0.49-0.84)^{* *}$ \\
\hline \multicolumn{3}{|l|}{ Physical activity } \\
\hline Low & 1.00 & \\
\hline Moderate & $1.01(0.70-1.45)$ & \\
\hline High & $0.92(0.66-1.27)$ & \\
\hline Insufficient fruit and vegetables & $0.96(0.65-1.43)$ & \\
\hline \multicolumn{3}{|l|}{ Subjective health status } \\
\hline Very/good & 1.00 & 1.00 \\
\hline Moderate & $1.43(1.12-1.83)^{* *}$ & $1.41(0.95-2.10)$ \\
\hline Bad/very bad & $1.44(0.77-2.68)$ & $1.27(0.62-2.58)$ \\
\hline \multicolumn{3}{|l|}{ Activity limitation } \\
\hline None & 1.00 & 1.00 \\
\hline Mild & $1.13(0.84-1.52)$ & $0.92(0.59-1.45)$ \\
\hline Moderate & $1.30(0.90-1.88)$ & $0.92(0.58-1.48)$ \\
\hline Severe/extreme & $2.10(1.12-3.93)^{*}$ & $1.60(0.70-3.64)$ \\
\hline $\begin{array}{l}\text { Social cohesion index (range 9-72); } \\
\text { mean (SD) }\end{array}$ & $1.01(0.9-1.03)$ & \\
\hline \multicolumn{3}{|l|}{ Outpatient visits in past 12 months } \\
\hline 0 & $\begin{array}{l}1.00 \\
1.00\end{array}$ & $\begin{array}{c}1.00 \\
114(080-163)\end{array}$ \\
\hline $1-4$ & $1.28(0.84-1.96)$ & $1.14(0.80-1.63)$ \\
\hline 5 or more & $1.94(1.34-2.81)^{* * *}$ & $1.93(1.48-2.51)^{* * *}$ \\
\hline${ }^{* * *} p<<0.001 ; * * p<0.01 ; * p<0.5$ & & \\
\hline
\end{tabular}

confirms previous studies in women. ${ }^{3}$ Further initiatives are required to address the high rate of hypertension in this population group. Unlike in other studies, ${ }^{13-15,17}$ this study did not find any effect of gender, age, level of education and geolocality on hypertensive status.

In terms of health variables, this study was in agreement with other studies, ${ }^{4,10,13,14,18,31}$ that having had a stroke, being overweight and having had more out-patients care visits in the past 12 months were associated with hypertension. Unlike some other studies, ${ }^{10,13,21,23-25,33}$ this study did not find insufficient fruit and

\begin{tabular}{|c|c|c|c|}
\hline \multicolumn{4}{|c|}{$\begin{array}{c}\text { TABLE 3. MULTIVARIATE LOGISTIC REGRESSION OF AWARENESS, } \\
\text { TREATMENT AND CONTROL RATES OF HYPERTENSION AMONG } \\
\text { OLDER ADULTS IN SOUTH AFRICA }\end{array}$} \\
\hline & $\begin{array}{c}\text { Awareness } \\
(30.3 \%)\end{array}$ & $\begin{array}{l}\text { Treatment } \\
(24.8 \%)\end{array}$ & $\begin{array}{c}\text { Control of treated } \\
(48.8 \%)\end{array}$ \\
\hline & AOR $(95 \% C I)$ & $A O R(95 \% C I)$ & AOR $(95 \% C I)$ \\
\hline \multicolumn{4}{|l|}{ Gender } \\
\hline Female & 1.00 & 1.00 & 1.00 \\
\hline Male & $0.68(0.51-0.90)^{* *}$ & $0.67(0.50-0.88)^{* *}$ & $1.09(0.81-1.46)$ \\
\hline \multicolumn{4}{|l|}{ Age } \\
\hline $50-59$ & 1.00 & 1.00 & 1.00 \\
\hline $60-69$ & $1.70(1.16-2.48)^{* *}$ & $1.89(1.38-2.58)^{* * *}$ & $0.73(0.55-0.95)$ \\
\hline 70 and over & $1.77(1.22-2.59)^{* *}$ & $2.15(1.40-3.30)^{* * *}$ & $0.73(0.50-1.06)$ \\
\hline \multicolumn{4}{|l|}{ Population group } \\
\hline African black & 1.00 & 1.00 & 1.00 \\
\hline White & $0.81(0.40-1.62)$ & $0.97(0.52-1.83)$ & $0.89(0.44-1.80)$ \\
\hline Coloured & $1.00(0.65-1.52)$ & $1.09(0.73-1.63)$ & $0.80(0.58-1.10)$ \\
\hline Indian or Asian & $1.08(0.56-2.07)$ & $1.45(0.73-2.91)$ & $1.25(0.64-2.45)$ \\
\hline \multicolumn{4}{|l|}{ Marital status } \\
\hline Single & 1.00 & 1.00 & 1.00 \\
\hline Married & $1.38(0.83-2.29)$ & $1.50(0.85-2.66)$ & $1.44(0.90-2.29)$ \\
\hline Separated/divorced & $1.17(0.69-1.97)$ & $1.11(0.62-1.99)$ & $1.11(0.65-2.45)$ \\
\hline Widow & $1.67(0.96-2.92)$ & $1.45(0.81-2.62)$ & $1.51(0.93-2.46)$ \\
\hline \multicolumn{4}{|l|}{ Educational level } \\
\hline No schooling & 1.00 & 1.00 & 1.00 \\
\hline Less than primary & $0.96(0.65-1.52)$ & $1.03(0.67-1.58)$ & $0.99(0.64-1.54)$ \\
\hline Primary & $1.10(0.72-1.68)$ & $1.03(0.65-1.61)$ & $1.04(0.73-1.49)$ \\
\hline Secondary & $0.94(0.65-1.38)$ & $1.09(0.75-1.59)$ & $1.54(1.04-2.27)^{*}$ \\
\hline \multicolumn{4}{|l|}{ Wealth } \\
\hline Low & 1.00 & 1.00 & 1.00 \\
\hline Medium & $1.43(0.98-2.08)$ & $1.36(0.84-2.20)$ & $0.75(0.49-1.15)$ \\
\hline High & $1.55(1.00-2.40)^{*}$ & $1.34(0.75-2.40)$ & $0.93(0.64-1.33)$ \\
\hline \multicolumn{4}{|l|}{ Geolocality } \\
\hline Rural & 1.00 & 1.00 & 1.00 \\
\hline Urban & $1.27(0.95-1.71)$ & $1.30(0.84-2.01)$ & $1.17(0.87-1.58)$ \\
\hline \multicolumn{4}{|l|}{$\begin{array}{l}\text { Outpatient visits in } \\
\text { past } 12 \text { months }\end{array}$} \\
\hline 0 & 1.00 & 1.00 & 1.00 \\
\hline $1-4$ & $1.85(1.10-3.11)^{*}$ & $1.94(1.20-3.12)^{* *}$ & $0.85(0.61-1.17)$ \\
\hline 5 or more & $4.49(3.02-6.66)^{* * *}$ & $5.95(3.96-8.95)^{* * *}$ & $=0.87(0.63-1.19)$ \\
\hline$* * * p<0.001 ; * * p$ & $1 ; * p<0.5$ & & \\
\hline
\end{tabular}

vegetable intake, smoking, being physically inactive and having more limitations in activities of daily living to be associated with hypertension. The finding that current alcohol use was protective for hypertension in this study may be in line with some previous studies where light-to-moderate alcohol consumption decreased hypertension risk in women and increased the risk in men. ${ }^{21}$

The rates of awareness, treatment and control among the hypertensive participants in the present study (38.1, 32.7 and $17.1 \%$, respectively) were as low as in some studies in rural China (35.2, 28.7 and 1.0\%), ${ }^{10}$ Senegal $\left(49.5,37.0\right.$ and 5.7\%), ${ }^{4}$ and Italy $(65.6,59.5$ and $10.5 \%) .{ }^{18}$ They were however lower than in studies in Costa Rica $74.9 \%$ aware and more than half controlled) $)^{7}$ and in the USA ( $74 \%$ aware and $51.6 \%$ controlled among men and $37 \%$ controlled among women). ${ }^{34}$

As found in some other studies, in this study, women were more frequently aware of their hypertension and more frequently treated. ${ }^{7,35}$ They were not significantly more frequently controlled than men, though, as found in other studies. ${ }^{7,36}$ In the group of individuals who were unaware of their hypertension, it may have been because of multiple factors, such as never having been screened for hypertension, having been previously diagnosed but had forgotten the diagnosis, the medical provider had not considered their blood pressure levels to be sufficiently elevated to warrant the diagnosis, or had had inadequate health education and limited access to healthcare services. ${ }^{9,35}$ Therefore, more efforts, such as public health education and a blood pressuremonitoring system should be included for the older age group, 
particularly men, to improve their unsatisfactory awareness, treatment and control of hypertension. ${ }^{10}$

\section{Limitations of the study}

This study had several limitations. Firstly, the self-report of health variables such as tobacco or alcohol use should be interpreted with caution; it is possible that respondents under-reported, especially females. As in many studies, arterial blood pressure was measured three times during a single session (two hours), which may have led to an overestimation of the prevalence of hypertension. In addition, the awareness and treatment rate of hypertension was solely assessed by individual self-report. Furthermore, this study was based on data collected in a crosssectional survey. We cannot, therefore, ascribe causality to any of the associated factors in the study.

\section{Conclusion}

This study revealed high rates of hypertension among older adults (50 years and more) in South Africa, which put them at risk for cardiovascular disease. The percentages of hypertensives who were aware of, treated for and controlled were very low. These data underscore the urgent need to strengthen the public health education and blood pressure-monitoring systems to better manage hypertension among older adults in South Africa. Community healthcare workers in their new role in South Africa could screen for hypertension among older adults using a primary care 'high-risk' approach once every two years. This screening process would enable the health system to identify and cater for the needs of this vulnerable population group. ${ }^{37}$

Funding was provided predominantly from the National Department of Health with additional funding provided by the United States National Institute on Aging through an interagency agreement with the World Health Organisation, and the Human Sciences Research Council, South Africa.

\section{References}

1. Rayner B. Hypertension: detection and management in South Africa Nephron Clin Pract 2010; 116(4): c269-273.

2. Mash B, Fairall L, Adejayan O, et al. A morbidity survey of South African primary care. PLoS One 2012; 7(3): e32358.

3. Steyn K, Gaziano TA, Bradshaw D, et al. Hypertension in South African adults: results from the Demographic and Health Survey, 1998. J Hypertens 2001; 19(10): 1717-1725.

4. Macia E, Duboz P, Gueye L. Prevalence, awareness, treatment and control of hypertension among adults 50 years and older in Dakar, Senegal. Cardiovasc J Afr 2011; 22: 1-5.

5. Mufunda J, Scott LJ, Chifamba J, et al. Correlates of blood pressure in an urban Zimbabwean population and comparison to other populations of African origin. J Hum Hypertens 2000; 14(1): 65-73.

6. Negin J, Cumming R, de Ramirez SS, et al. Risk factors for noncommunicable diseases among older adults in rural Africa. Trop Med Intern Health 2011; 16(5): 640-646.

7. Méndez-Chacón E, Santamaría-Ulloa C, Rosero-Bixby L. Factors associated with hypertension prevalence, unawareness and treatment among Costa Rican elderly. BMC Public Health 2008; 8: 275.

8. Duda RB, Anarfi JK, Adanu RM, et al. The health of the 'older women' in Accra, Ghana: results of the Women's Health Study of Accra. J Cross Cult Gerontol 2011; 26(3): 299-314.

9. Lima e Costa MF, Peixoto SV, et al. Health behaviors among older adults with hypertension, Brazil, 2006. Rev Saude Publica 2009; 43(Suppl 2): 18-26.
10. Pang W, Li Z, Sun Z, et al. Prevalence of hypertension and associated factors among older rural adults: results from Liaoning Province, China. Med Princ Pract 2010; 19(1): 22-27.

11. Ruixing Y, Jiaqiang D, Dezhai Y, et al. Effects of demographic characteristics, health-related behaviors and lifestyle factors on the prevalence of hypertension for the middle-aged and elderly in the Guangxi Hei Yi Zhuang and Han populations. Kidney Blood Press Res 2006; 29(5): 312-320.

12. Erem C, Hacihasanoglu A, Kocak M, et al. Prevalence of prehypertension and hypertension and associated risk factors among Turkish adults: Trabzon Hypertension Study. J Public Health (Oxf) 2009; 31(1): 47-58.

13. Tsai AC, Liou JC, Chang MC. Interview to study the determinants of hypertension in older adults in Taiwan: a population based crosssectional survey. Asia Pac J Clin Nutr 2007; 16(2): 338-345.

14. Hendriks ME, Wit FW, Roos MT, et al. Hypertension in sub-Saharan Africa: cross-sectional surveys in four rural and urban communities. PLoS One 2012; 7(3): e32638.

15. Kaplan MS, Huguet N, Feeny DH, McFarland BH. Self-reported hypertension prevalence and income among older adults in Canada and the United States. Soc Sci Med 2010; 70(6): 844-849.

16. Teo GS, Idris MN. Prevalence of hypertension among Chinese elderly and its relationship to behavioural and nutritional factors. Med $J$ Malaysia 1996; 51(1): 33-40.

17. Agyemang C. Rural and urban differences in blood pressure and hypertension in Ghana, West Africa. Public Health 2006; 120(6): 525-533.

18. Ngoungou EB, Aboyans V, Kouna P, et al. Prevalence of cardiovascular disease in Gabon: A population study. Arch Cardiovasc Dis 2012; 105(2): 77-83.

19. Prencipe M, Casini AR, Santini M, et al. Prevalence, awareness, treatment and control of hypertension in the elderly: results from a population survey. J Hum Hypertens 2000; 14(12): 825-830.

20. Long AN, Dagogo-Jack S. Comorbidities of diabetes and hypertension: mechanisms and approach to target organ protection. J Clin Hypertens (Greenwich) 2011; 13(4): 244-251.

21. Giday A, Tadesse B. Prevalence and determinants of hypertension in rural and urban areas of southern Ethiopia. Ethiop Med J 2011; 49(2): 139-147.

22. De Ramirez SS, Enquobahrie DA, Nyadzi G, et al. Prevalence and correlates of hypertension: a cross-sectional study among rural populations in sub-Saharan Africa. J Hum Hypertens 2010; 24(12): 786-795.

23. Wang L, Manson JE, Gaziano JM, et al. Fruit and vegetable intake and the risk of hypertension in middle-aged and older women. Am J Hypertens 2012; 25(2): 180-189.

24. Zhao D, Qi Y, Zheng Z, et al. Dietary factors associated with hypertension. Nat Rev Cardiol 2011; 8(8): 456-465.

25. Caskie GI, Sutton MC, Margrett JA.The relation of hypertension to changes in ADL/IADL limitations of Mexican american older adults. $J$ Gerontol B Psychol Sci Soc Sci 2010; 65B(3): 296-305.

26. Mujahid MS, Diez Roux AV, Morenoff JD, et al. Neighborhood characteristics and hypertension. Epidemiology 2008; 19(4): 590-598.

27. Chobanian AV, Bakris GL, Black HR, et al. Seventh report of the Joint National Committee of Prevention, Detection, Evaluation, and Treatment of High Blood Pressure. Hypertension 2003; 42: 1206-1252.

28. World Health Organisation (WHO). Guidelines for controlling and monitoring the tobacco epidemic. Geneva, Switzerland: WHO, 1998.

29. World Health Organisation (WHO). Global Physical Activity Surveillance. (http://www.who.int/chp/steps/GPAQ/en/index.html, accessed 2 December 2010), 2009.

30. Chatterji S, Kowal P, Mathers C, et al. The health of aging populations in China and India. Health Aff (Millwood) 2008; 27(4): 1052-1063.

31. Mufunda J, Mebrahtu G, Usman A, et al. The prevalence of hypertension and its relationship with obesity: results from a national blood pressure survey in Eritrea. J Hum Hypertens 2006; 20(1): 59-65.

32. Banda JA, Clouston K, Sui X, et al. Protective health factors and incident hypertension in men. Am J Hypertens 2010; 23(6): 599-605.

33. Sesso HD, Cook NR, Buring JE, et al. Alcohol consumption and the risk of hypertension in women and men. Hypertension 2008; 51(4): 1080-1087.

34. Ostchega Y, Dillon CF, Hughes JP, et al. Trends in hypertension preva- 
lence, awareness, treatment, and control in older US adults: data from the National Health and Nutrition Examination Survey 1988 to 2004. $J$ Am Geriatr Soc 2007; 55(7): 1056-1065.

35. Brindel P, Hanon O, Dartigues JF, et al. Prevalence, awareness, treatment, and control of hypertension in the elderly: the Three City study. $J$ Hypertens 2006; 24(1): 51-58.
36. Satish S, Markides KS, Zhang D, Goodwin JS. Factors influencing unawareness of hypertension among Older Mexican Americans. Preventive Med 1997; 26: 645-650.

37. John J, Muliyil J, Balraj V. Screening for hypertension among older adults: a primary care 'high risk' approach. Indian J Community Med 2010; 35(1): 67-69.

\section{...continued from page 65}

reference to the alternative classification scheme of the European Society of Cardiology. ${ }^{11}$ In the latter scheme, cardiomyopathy is regarded as a structural and functional abnormality of the myocardium that is not due to hypertension, coronary artery disease, valvular heart disease, pericardial disease, or congenital heart disease. Furthermore, cardiomyopathy is sub-classified into familial/genetic or non-familial/non-genetic types.

I have found that the European Society of Cardiology classification lends itself well to the clinical evaluation of patients with unexplained heart failure in the African setting..$^{12,13}$ It would be of interest to know the opinion of the authors and that of the Pan-African Society of Cardiology (as suggested by the authors) on the utility of the European classification of cardiomyopathy compared to the version of the American Heart Association in the African environment.

Finally, the authors make a case for a new and unique classification of myocardial disorders for Africa. It is not clear why Africans should be an exception to other populations of the world. We have shown previously that while the burden of disease may be higher for certain forms of cardiomyopathy in Africa, the pathophysiological features of the cardiomyopathies are likely to be the same in all continental populations..$^{13,14}$ Therefore, the aspiration of the Pan-African Society of Cardiology should probably be to contribute to the development of a universal classification of cardiomyopathy for all people in the world, possibly under the auspices of the World Health Organisation or the World Heart Federation.

\section{BONGANI M MAYOSI, DPhil, FCP (SA), bongani.mayosi@ uct.ac.za}

Department of Medicine, Old Groote Schuur Hospital, Cape Town, South Africa

\section{References}

1. Falase AO, Ogah OS. Cardiomyopathies and myocardial disorders in Africa: present status and the way forward. Cardiovasc J Afr 2012; 23: $552-562$.
2. Sliwa K, Damasceno A, Mayosi BM. Epidemiology and etiology of cardiomyopathy in Africa. Circulation 2005; 112(23): 3577-3583.

3. Mayosi BM. Contemporary trends in the epidemiology and management of cardiomyopathy and pericarditis in sub-Saharan Africa. Heart 2007; 93(10): 1176-1183.

4. Ker J, Van Der Merwe C. Isolated left ventricular non-compaction as a cause of thrombo-embolic stroke: a case report and review. Cardiovasc J S Afr 2006; 17: 146-147.

5. Ali SK. Unique features of non-compaction of the ventricular myocardium in Arab and African patients. Cardiovasc J Afr 2008; 19: 241-245.

6. Massoure PL, Lamblin G, Bertani A, Eve O, Kaiser E. Rare cause of heart failure in an elderly woman in Djibouti: left ventricular non compaction. Med Trop (Mars) 2011; 71: 505-507.

7. Peters F, Dos Santos C, Essop R. Isolated left ventricular non-compaction with normal ejection fraction. Cardiovasc J Afr 2011; 22: 90-93.

8. Peters F, Khandheria BK, dos Santos C, Matioda H, Mogogane MT, Essop MR. Isolated left ventricular noncompaction in identical twins. Am J Cardiol 2012; 110(8): 1175-1179.

9. Kruse M, Schulze-Bahr E, Corfield V, et al. Impaired endocytosis of the ion channel TRPM4 is associated with human progressive familial heart block type I. J Clin Invest 2009; 119(9): 2737-2744.

10. Maron BJ, Towbin JA, Thiene G, et al. Contemporary definitions and classification of the cardiomyopathies: An American Heart Association scientific statement from the Council on Clinical Cardiology, Heart Failure and Transplantation Committee; Quality of Care and Outcomes Research and Functional Genomics and Translational Biology Interdisciplinary working groups; and Council on Epidemiology and Prevention. Circulation 2006; 113(14): 1807-1816.

11. Elliott P, Andersson B, Arbustini E, et al. Classification of the cardiomyopathies: a position statement from the European Society of Cardiology working group on myocardial and pericardial diseases. Eur Heart J 2008; 29: 270-276.

12. Ntusi NBA, Badri M, Gumedze F, Wonkam A, Mayosi BM. Clinical characteristics and outcomes of familial and idiopathic dilated cardiomyopathy in Cape Town: A comparative study of 120 cases followed up over 14 years. S Afr Med J 2011; 101(6): 399-404.

13. Ntusi NBA, Wonkam A, Shaboodien G, Badri M, Mayosi BM. Frequency and clinical genetics of familial dilated cardiomyopathy in Cape Town: Implications for the evaluation of patients with unexplained cardiomyopathy. S Afr Med J 2011; 101(6): 394-398.

14. Watkins DA, Hendricks N, Shaboodien G, et al. Clinical features, survival experience, and profile of plakophylin-2 gene mutations in participants of the Arrhythmogenic Right Ventricular Cardiomyopathy Registry of South Africa. Heart Rhythm 2009; 6(11, Supplement 1): S10-S7. 